The Israeli Journal of Aquaculture - Bamidgeh, IJA_72.2020.1227608, 13 pages

CCBY-NC-ND-4.0 • https://doi.org/10.46989/001c.21470

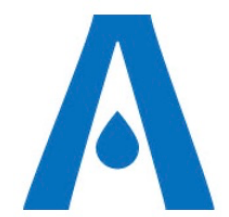

The $I J A$ is a peer-reviewed open-access, electronic journal, freely available without charge to users

Produced by the AquacultureHub non-profit Foundation Sale of $I J A$ papers is strictly forbidden

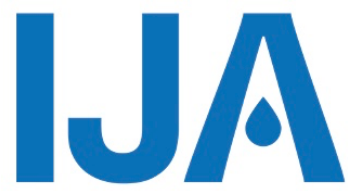

\title{
Dietary Quillaja saponin improves growth and resistance against acute hyposalinity shock in the black tiger shrimp Penaeus monodon post larvae
}

\author{
Yashier U. Jumah ${ }^{1,3}$, Barry Leonard M. Tumbokon' ${ }^{2}$, Augusto E. Serrano Jr.,2* \\ ${ }^{1}$ Institute of Aquaculture, College of Fisheries and Ocean Sciences, University of the \\ Philippines Visayas, Miagao, Iloilo, Philippines \\ ${ }^{2}$ National Institute of Molecular Biology and Biotechnology, University of the Philippines \\ Visayas, Miagao, Iloilo, Philippines \\ ${ }^{3}$ Aquaculture Department, College of Fisheries, Mindanao State University - Tawi-Tawi \\ College of Technology and Oceanography, Sanga-Sanga, Bongao, Tawi-Tawi, Philippines
}

Key words: triterpenoid saponin, Quillaja saponaria, attractability, immune enhancer, optimal inclusion, cumulative mortality

\begin{abstract}
Acute hyposalinity stress in shrimp ponds is a natural occurrence during the rainy season and the provision of functional ingredients that will elicit resistance to this stress is needed. Quillaja saponin (QS), a triterpenoid saponin derived from the bark of Quillaja saponaria, is reported to trigger innate immunity in vitro and in vivo in shrimps. The present study aims to evaluate its potential as growthpromoter and its immune-enhancement effects against salinity stress. Three separate experiments were done: (a) an attractability test; (b) a 30-day feeding trial to determine optimal inclusion of QS; and (3) an acute hyposalinity stress test following feeding the experimental diets. Attractability tests showed that all the Quillaja saponin inclusions significantly attracted more shrimps than the control diet $(p<0.05)$. In the feeding trial, 5 experimental diets containing 0.0 , $0.15,0.30,0.45$, and $0.60 \mathrm{~g} \mathrm{~kg}^{-1}$ QS (QS 0, QS 15, QS 30, QS 45 and QS 60, respectively) were fed to groups of shrimps. Results showed that the final average body weight (FABW), feed intake (FI), weight gain (WG), specific growth rate (SGR), feed conversion ratio (FCR), and protein efficiency ratio (PER) values of shrimps in the QS 30 and 45 groups were significantly higher than that of the control group; the values of those in QS 15 and 60 groups were not significantly different from those of the QS 0 group. The optimal inclusion level of dietary $Q S$ was estimated to be $0.36 \mathrm{~g} \mathrm{~kg}^{-1}$. In the acute hyposalinity stress test, shrimps were fed with the experimental diets for 2 weeks and then transferred from 24 PSU salinity media to 2 PSU. All QS groups showed lower cumulative mortality rate than that of the QS 0 group except for the QS 60; QS 30 groups exhibited significantly the lowest. The estimated level of $Q S$ that elicited the lowest cumulative mortality rate was $0.33 \mathrm{~g} \mathrm{~kg}^{-1}$. In conclusion, the diets containing QS enhanced the shrimp's attractability, promoted both growth and immune response against acute hyposalinity stress at the optimal level of $0.36 \mathrm{~g} \mathrm{~kg}-1$ QS in the black tiger shrimp $P$. monodon.
\end{abstract}

* Corresponding author. A.E. Serrano Jr, e-mail: aeserrano@up.edu.ph 


\section{Introduction}

Penaeid shrimps are euryhaline invertebrates and are cultured under a wide variety of conditions in many tropical and subtropical areas in the world. The optimal salinity range for the culture of Penaeus monodon is 15-25 ppt (Ferraris et al., 1986). However, shrimps are generally exposed to climatic changes that affect the physicochemical quality of water, such as salinity. These changes may result in stress to the shrimps during culture period. Previous studies have demonstrated that the salinity tolerance of Penaeus monodon ranged from 1 to $57 \%$. The most suitable salinity range for growth is from 10 to $35 \%$ o (Ye et al., 2009; Wang \& Chen, 2006). In the outdoor rearing ponds, the fluctuation of salinity is a primary reason causing failure of shrimp production. This is because salinity changes over a particular range can affect their immune system and make them highly vulnerable to pathogens (Nikapitiya et al., 2014). Drastic salinity changes affect their metabolism, growth, molting and survival (Staples \& Heales, 1991; Chen et al., 1995), feed intake and energy utilization for osmoregulation (Silva et al., 2010) and other biochemical and physiological parameters of the shrimps in response to stress (Chen \& Lin, 1994; Perazzolo et al., 2002). Salinity stress induces oxidative stress in Penaeus monodon i.e. on $\mathrm{O}^{2-}$ production and antioxidant enzymes in the muscle of the shrimp (Wang et al., 2008).

Enhancement of the shrimp's immune activity is a primary consideration in the control of various diseases (Liu et al., 2011). Various plant extracts have been evaluated to stimulate shrimp nonspecific immune responses (Chang et al., 2012; Kongchum et al., 2016; Yin et al., 2014). These plant extracts that have been used in aquaculture contain bioactive factors such as flavonoids, phenols, polysaccharides, organic acids, alkaloids, glycosides, terpenoids, essential oils, tannins, saponins, and steroids. All of these factors may promote growth, enhance immune system, promote antimicrobial effects, stimulate the appetite, and exhibit anti-stress properties (Awad \& Awaad, 2017; Van hai, 2017). Plant extracts have the advantage of being safe, are less expensive, efficacious, and globally available; they are biodegradable and easily applied e.g. spraying over pelletized diets (Logambal et al., 2000).

One of the plant extract candidates is saponin found in a wide variety of plants which contain either a steroid or triterpenoid aglycone to which one or more sugar chains are attached (Oda et al., 2003). Saponins extracted from soapbark tree (Quillaja saponaria) and Mojave yucca (Yucca schidigera) have proven to be very promising ingredients for aquafeeds as natural growth promoters (Acosta et al., 2019). However, there have been reports of the damage of saponin to both fish and shrimps (Roy \& Munshi, 1989; Roy et al., 1990; Homechaudhuri \& Banerjee, 1991; Terazaki et al., 1980; Chen et al., 1996). It is the aim of the present study to evaluate Quillaja saponin as either growth promoter and/or immunostimulant against acute hyposalinity stress at the organismic level in $P$. monodon post larvae.

\section{Materials and Methods}

\section{Experimental shrimps and set-up}

The study was conducted in the wet laboratory of the National Institute of Molecular Biology and Biotechnology (NIMBB), University of the Philippines Visayas (UPV), Miagao, Iloilo, Philippines.

A total of 450 post-larvae of 20 black tiger shrimps Penaeus monodon (initial body weight (IBW) of $0.01 \mathrm{~g}$ ), were randomly stocked in each of 15 experimental units. These post-larvae were purchased from the SNB hatchery located at Brgy. Bongol San Vicente, Guimbal, Iloilo, about $12 \mathrm{~km}$ to the wet laboratory of the university. The shrimp larvae which were certified White Spot Syndrome Virus (WSSV) and Vibrio parahaemolyticus-free were transported in plastic bags half-filled with sea water infused with oxygen. Upon arrival in the laboratory, shrimps were slowly acclimatized to ambient temperature and salinity of the water in a 250-L fiberglass holding tank. The shrimp were fed with the basal (i.e. control) diet for 3 days prior to distribution into the 15 experimental tanks. 


\section{Diet preparation}

Five diets containing various concentrations of purified saponin $(0,0.15,0.30,0.45$ and $0.60 \mathrm{~g} \mathrm{~kg}^{-1}$ diet) (Sigma product no. S-4521 extracted from the bark of the soap tree Quillaja saponaria, Sigma-Aldrich Corp., MO, USA) were prepared. The composition of the experimental diets are presented in Table 1. Dry ingredients were sieved and weighed individually, and were thoroughly mixed in a large transparent plastic bag. Liquid ingredients such as lecithin, fish oil and water-dissolved purified Quillaja saponin were added next. Gelatinized high-grade flour (i.e. cooked in distilled water to the desired consistency) was added last and the moist mixture was manually kneaded inside the plastic bag into dough. Prior to oven drying, the dough was steamed for $15 \mathrm{~min}$, rolled out thinly on a metal tray onto which small square size portions were sliced in place using a knife. Oven drying was done for $24 \mathrm{~h}$ at $60^{\circ} \mathrm{C}$ until the moisture reached about $<10 \%$. The ovendried experimental diets were collected in square-shaped pieces, put in plastic bags and stored at $-20^{\circ} \mathrm{C}$ until use.

\section{Diet attractability test}

Nine separate attractability tests were conducted using rectangular glass tanks with multiple chambers (Suresh et al., 2011) (Figure 1). Each tank consisted of 3 major chambers (an acclimatization chamber, a middle chamber, and a feeding chamber) that were separated with glass partitions. The feeding chamber consisted of 5 sub-chambers measuring $6 \times 5 \mathrm{~cm}$.

Each glass tank ( $90 \times 50 \times 30 \mathrm{~cm} \mathrm{~L}, W$ and $\mathrm{H}$, respectively) consisted of an acclimatization chamber at one end and feeding chambers at the other end separated by a liftable glass partition. The tanks were set up in a room with only fluorescent light. All assessments were conducted at the same time of the day commencing at 09:30 h. Diet attractability was performed on the 5 experimental diets in three simultaneous runs. Fifteen randomly selected shrimps were acclimatized for $1 \mathrm{~h}$ in the acclimatization chamber, and then $2 \mathrm{~g}$ of each experimental diet were placed separately in each of the feeding sub-chambers. Following the lifting of the glass partition, the number of shrimps that entered each of the feeding chambers was recorded. Diet attractability was expressed as percent of shrimp that were inside a particular feeding chamber containing a particular experimental diet after 1, 2, 5, 10 and 15 min following the lifting of the glass partition.

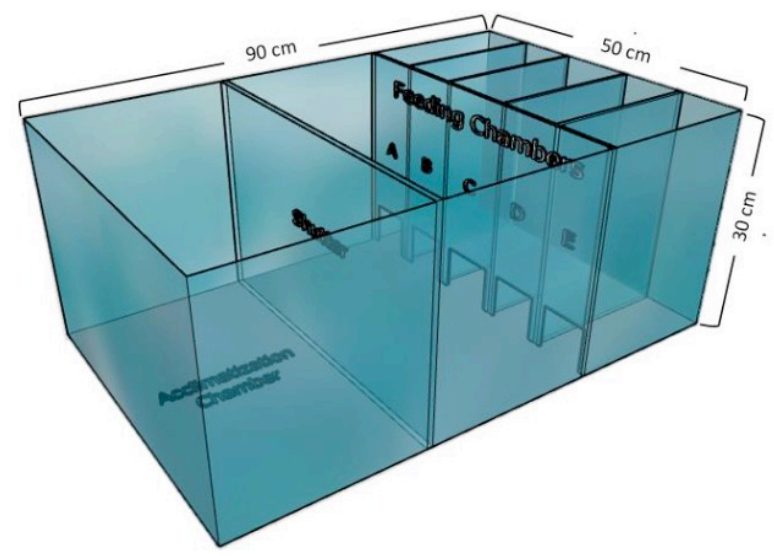

Figure 1 Schematic diagram of the tank used for the attractability test. 
Table 1 Feed composition and proximate analysis of experimental diets containing Quillaja saponin for Penaeus monodon post larvae growth trial (g $1000 \mathrm{~g} \mathrm{diet}^{-1}$ ) for 30 days. $^{2}$

\begin{tabular}{lrrrrr}
\hline Ingredients & QS 0 & QS 15 & QS 30 & QS 45 & QS 60 \\
\hline Peruvian fish & 200.0 & 200.0 & 200.0 & 200.0 & 200.0 \\
meal & 340.0 & 340.0 & 340.0 & 340.0 & 340.0 \\
Shrimp meal & 210.0 & 210.0 & 210.0 & 210.0 & 210.0 \\
Squid meal & 34.8 & 34.65 & 34.5 & 34.35 & 34.2 \\
CMC & 10.0 & 10.0 & 10.0 & 10.0 & 10.0 \\
Vitamin mix & 10.0 & 10.0 & 10.0 & 10.0 & 10.0 \\
Mineral mix & 0.2 & 0.2 & 0.2 & 0.2 & 0.2 \\
BHT & 5.0 & 5.0 & 5.0 & 5.0 & 5.0 \\
Lecithin & 40.0 & 40.0 & 40.0 & 40.0 & 40.0 \\
Cod liver oil & 150.0 & 150.0 & 150.0 & 150.0 & 150.0 \\
Starch & 0.0 & 0.15 & 0.30 & 0.45 & 0.60 \\
Quillaja saponin & 1000.0 & 1000.0 & 1000.0 & 1000.0 & 1000.0 \\
Total & & & & & \\
& & & & & \\
Proximate analysis (\%) & dry weight basis) & 56.78 & 56.46 & 56.49 & 56.6 \\
Crude Protein & 56.33 & 5.17 & 5.14 & 5.12 & 5.26 \\
Crude Fat & 5.69 & 2.34 & 2.4 & 2.57 & 2.35 \\
Crude Fiber & 1.98 & 9.8 & 9.79 & 9.45 & 9.52 \\
Moisture & 10 & 12.8 & 12.5 & 12.41 & 12.49 \\
Ash & 12.91 & 13.11 & 13.71 & 13.96 & 13.78 \\
NFE & 13.09 & & & & \\
\hline
\end{tabular}

${ }^{1}$ Vitamin mix ( $\mathrm{mg} \mathrm{kg}^{-1}$ dry diet unless otherwise stated): Vitamin A 1 200,000 IU, Vitamin D3 200,000 IU, Vitamin E 20,000 IU, Vitamin B1 8,000 IU, Vitamin B2 8,000 IU, Vitamin B6 5,000 IU, Vitamin B12 $2000 \mu \mathrm{g}$, Niacin 40,000 $\mu \mathrm{g}$, Calcium pantothenate $20,000 \mu \mathrm{g}$, Biotin $40 \mu \mathrm{g}$, Folic acid 1,800 $\mu \mathrm{g}$, Ethoxyquin $500 \mu \mathrm{g}$, Carrier q.s add to make $1 \mathrm{~kg}$; ${ }^{2}$ Mineral mix ( $\mathrm{mg} \mathrm{kg}^{-1}$ dry diet unless otherwise stated): Iron $400 \mathrm{mg}$; Manganese $100 \mathrm{mg}$; Zinc 400 mg; Copper 40 mg; Iodine 18 mg; Cobalt 0.2 mg; Selenium 2 mg.

\section{Feeding trial experiment}

Uniformed-sized post larval shrimps were distributed into 15 experimental containers in a completely randomized design (CRD) within a recirculation system. The system comprised a reservoir into which the collected effluent water from each of the experimental units was passed through a cloth fiber filter into the reservoir. Water from the reservoir was pumped onto an elevated filter (about $7 \mathrm{ft}$ ), equipped with a $50-\mathrm{L}$ capacity plastic container filled with sand and gravel; the water drained onto a lower biological filter container which contained sterilized empty oyster shells. The water coming from the biological filter was distributed through a pipe system into each of the experimental units. Feeding was done five times daily at 0700, 0930, 1200, 1430 , and $1700 \mathrm{~h}$. Siphoning off of about $50 \%$ of the total recirculated water volume with the waste and uneaten feeds was done every morning before the first feeding and water was replaced daily. Feeding rate was practically ad libitum starting at the basal rate of $30 \%$ body weight for the first 2 weeks and $20 \%$ for the last 2 weeks. Daily ration was closely monitored at each feeding time and adjusted accordingly either to stop feeding when no feeding activity was detected or to add more feeds when feeds were totally consumed in a short period of time. Water quality parameters such as salinity, temperature, $\mathrm{pH}$, and $\mathrm{DO}$ were measured daily while ammonia $\left(\mathrm{NH}_{3} / \mathrm{NH}_{4}{ }^{+}\right)$, nitrite $\left(\mathrm{NO}_{2}^{-}\right)$and nitrate $\left(\mathrm{NO}_{3}{ }^{-}\right)$were measured weekly using commercially available kits (API ${ }^{\circledR}$ MARINE).

\section{Growth response parameters}

Growth performance and feed utilization indices such as weight gain (WG), specific growth rate (SGR), feed conversion ratio (FCR), protein efficiency ratio (PER), and survival rate were estimated using the following formulae: 
WG $(g)=I B W-F B W$

SGR (\% daily) $=100 \times($ In FBW - In IBW $) / D$

Where: FBW - final body weight, IBW- initial body weight, D - number of days of culture.

FCR $=$ feed offered $(\mathrm{g}) /$ wet weight gain $(\mathrm{g})$

PER $=$ weight gain $(g) /$ protein fed $(g)$

Survival rate $=($ final number of shrimp $/$ initial number of shrimp $) \times 100$

At the start and termination of the trial, all shrimps in each feeding unit were carefully collected by a fine-meshed scoop net the bottom of which was blotted onto a clean paper towel, and the shrimps were placed into a small clear plastic cup and quickly weighed. Shrimps were weighed by batch using a digital top-loading balance.

\section{Acute salinity stress test}

A new batch of 450 of post larval shrimps were randomly distributed into a new set of 50- $\mathrm{L}$ containers- a total of 15 units of $50-\mathrm{L}$ plastic containers in a static water system. Shrimps were fed with the experimental diets at $25 \%$ body weight for 15 days. The experimental procedure was similar to that of the growth trial except that the feeding period was only for 15 days. On the $15^{\text {th }}$ day, shrimps were transferred from a $24-p p t$ water medium to $2 \mathrm{ppt}$ in fifteen 10-L plastic container and were monitored for $24 \mathrm{~h}$. Mortality was monitored every 15 min for $1 \mathrm{~h}$, then every hour for $4 \mathrm{~h}$, followed by every 4 hours for $12 \mathrm{~h}$. Water parameters such as $\mathrm{pH}$, salinity, DO and temperature were monitored, and about $25 \%$ of water was carefully replaced daily. Shrimps continued to be fed 3 times a day with their corresponding experimental diets at $6 \%$ of $A B W$ and continued to receive aeration.

\section{Statistical analysis}

Statistical analysis was performed using Statistical Package for Social Sciences (SPSS, version 23). Percent data were transformed into arcsine values prior to analysis. Data were analyzed for homogeneity and normality of distribution and upon passing the tests, oneway analysis of variance (one-way ANOVA) was applied to test the statistical significance. Duncan's Multiple Range Test (DMRT) was used to rank the significance among treatments. The level of significance was set at $\alpha=0.05$. Data were presented as mean \pm standard error of the mean (SEM).

\section{Results}

The mean water quality parameters during the duration of the experiment are presented in Table 2. No major fluctuations occurred in the daily salinity, temperature, $\mathrm{pH}, \mathrm{DO}$, ammonia- $\mathrm{N}$, nitrite and nitrate.

Table 2 Means of water quality parameters during the feeding trial of the black tiger shrimp $P$. monodon post larvae fed with various dietary Quillaja saponin inclusions for 30 days

\begin{tabular}{llllll}
\hline Water Quality & \multicolumn{5}{c}{ Treatment } \\
\cline { 2 - 6 } Parameter & QS 0 & QS 15 & QS 30 & QS 45 & QS 60 \\
\hline Salinity (\%o) & $23.67 \pm 0.09$ & $23.67 \pm 0.09$ & $23.67 \pm 0.09$ & $23.67 \pm 0.09$ & $23.67 \pm 0.09$ \\
Temp. ( $\left.{ }^{\circ} \mathrm{C}\right)$ & $28.17 \pm 0.13$ & $28.19 \pm 0.14$ & $28.13 \pm 0.12$ & $28.14 \pm 0.12$ & $28.11 \pm 0.12$ \\
pH & $8.53 \pm 0.05$ & $8.48 \pm 0.05$ & $8.52 \pm 0.05$ & $8.53 \pm 0.04$ & $8.52 \pm 0.04$ \\
$\mathrm{DO}(\mathrm{ppm})$ & $6.86 \pm 0.11$ & $6.98 \pm 0.09$ & $6.86 \pm 0.10$ & $6.93 \pm 0.12$ & $6.82 \pm 0.09$ \\
$\mathrm{NH}_{3} / \mathrm{NH}_{4}{ }^{+}(\mathrm{ppm})$ & $0.20 \pm 0.03$ & $0.20 \pm 0.03$ & $0.20 \pm 0.03$ & $0.22 \pm 0.02$ & $0.20 \pm 0.03$ \\
$\mathrm{NO}_{2}{ }^{-}(\mathrm{ppm})$ & $0.00 \pm 0.00$ & $0.00 \pm 0.00$ & $0.00 \pm 0.00$ & $0.00 \pm 0.00$ & $0.00 \pm 0.00$ \\
$\mathrm{NO}_{3}{ }^{-}(\mathrm{ppm})$ & $6.00 \pm 0.53$ & $6.00 \pm 0.53$ & $6.00 \pm 0.53$ & $6.00 \pm 0.53$ & $6.00 \pm 0.53$ \\
\hline
\end{tabular}


Results of the attractability test showed that the level of dietary Quillaja saponin affected the attractability of the diet to the shrimp post larvae. In all the period, the diet QS 45 attracted the significantly the greatest number of shrimps, followed by diet QS 30 $(p<0.05)$ (Table 3). Attractability of the diets QS 0, QS 15 and QS 60 were not significantly different from each other $(p>0.05)$. All dietary saponin inclusions significantly attracted more shrimps than the control diet that started from 1 min until $15 \mathrm{~min}$.

Table 3 Attractability of individuals of shrimp P. monodon to the control and Quillaja saponin diets

\begin{tabular}{llllll}
\hline Treatment & \multicolumn{5}{c}{ Time $(\min )$} \\
\cline { 2 - 6 } & \multicolumn{1}{c}{1} & \multicolumn{1}{c}{2} & \multicolumn{1}{c}{5} & 10 & 15 \\
\hline QS 0 & $2.22 \pm 3.33^{\mathrm{c}}$ & $3.70 \pm 3.51^{\mathrm{d}}$ & $6.67 \pm 5.77^{\mathrm{d}}$ & $9.63 \pm 6.76^{\mathrm{d}}$ & $13.33 \pm 6.67^{\mathrm{d}}$ \\
QS 15 & $4.44 \pm 4.71^{\mathrm{c}}$ & $9.63 \pm 5.88^{\mathrm{cd}}$ & $16.30 \pm 10.06^{\mathrm{c}}$ & $25.93 \pm 13.10^{\mathrm{c}}$ & $34.07 \pm 16.14^{\mathrm{c}}$ \\
QS 30 & $11.11 \pm 4.71^{\mathrm{b}}$ & $19.26 \pm 9.69^{\mathrm{b}}$ & $29.63 \pm 11.60^{\mathrm{b}}$ & $42.22 \pm 11.06^{\mathrm{b}}$ & $55.56 \pm 12.47^{\mathrm{b}}$ \\
QS 45 & $17.04 \pm 5.88^{\mathrm{a}}$ & $28.15 \pm 6.48^{\mathrm{a}}$ & $43.70 \pm 10.60^{\mathrm{a}}$ & $65.93 \pm 15.79^{\mathrm{a}}$ & $82.22 \pm 16.33^{\mathrm{a}}$ \\
QS 60 & $5.93 \pm 4.01^{\mathrm{c}}$ & $13.33 \pm 5.77^{\mathrm{bc}}$ & $20.00 \pm 8.82^{\mathrm{c}}$ & $28.89 \pm 15.28^{\mathrm{c}}$ & $39.26 \pm 18.69^{\mathrm{c}}$ \\
\hline
\end{tabular}

Means having the same superscripts are not significantly different from each other $(p>0.05)$.

Low salinity challenge test

Results of the acute hyposalinity stress test showed that shrimps fed QS 30 exhibited significantly the highest survival rate of $88.9 \%$ followed by those fed QS 45 after $24 \mathrm{~h}$ following transfer from 24 PSU medium to 2 PSU salinity; these two groups were significantly different from each other $(p<0.05)$ (Figure 2 and Table 4). QS 0 group exhibited significantly the lowest survival rate of $48.9 \%$ which was not significantly different from those of QS 60 and QS 15 groups.

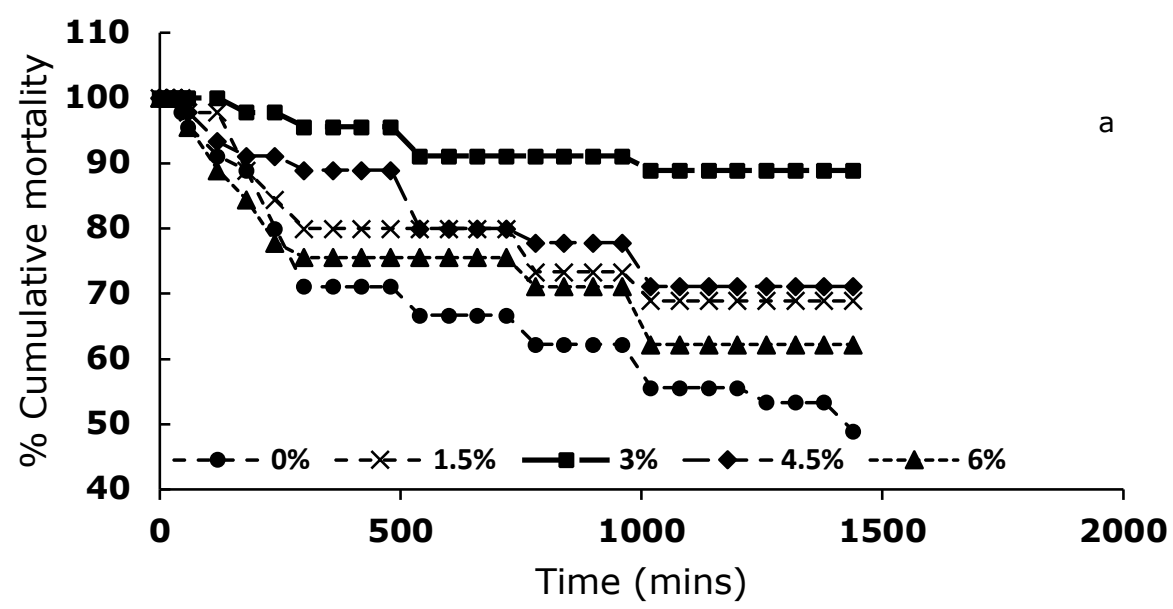

Figure 2 Cumulative mortality of black tiger shrimp post larvae in the acute hyposalinity challenge test following feeding diets containing various Quillaja saponin inclusions for 15 days.

Table 4 Final survival rate of shrimps after $24 \mathrm{~h}$ in 2 ppt salinity challenge test.

\begin{tabular}{rr}
\hline Treatment & Final survival rate \\
\cline { 2 - 2 } & $(\%)$ \\
\hline QS 0 & $48.89 \pm 11.76^{\mathrm{c}}$ \\
QS 15 & $68.89 \pm 4.44^{\mathrm{bc}}$ \\
QS 30 & $88.89 \pm 2.22^{\mathrm{a}}$ \\
QS 45 & $71.11 \pm 2.22^{\mathrm{b}}$ \\
QS 60 & $62.22 \pm 4.44^{\mathrm{bc}}$
\end{tabular}

Means having the same superscripts are not significantly different from each other $(p>0.05)$. 


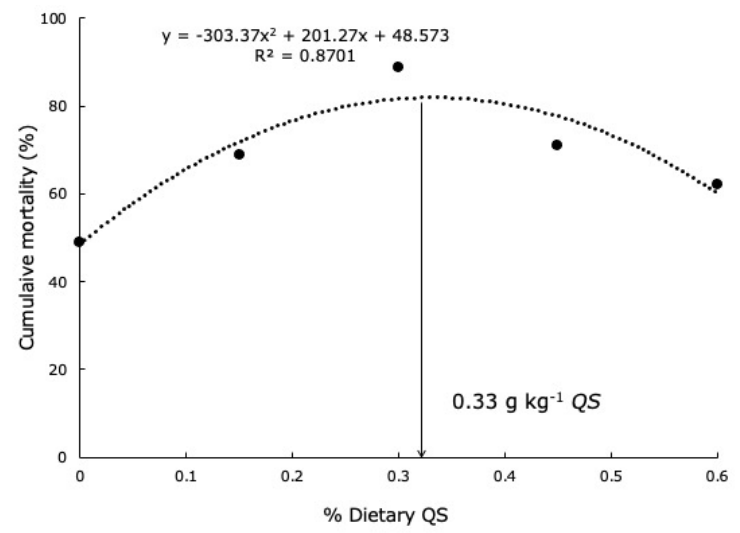

Figure 3 Estimation of the optimal level of dietary Quillaja saponin that elicit maximum final survival rate after a $24 \mathrm{~h}$ transfer from 24 practical salinity unit (PSU) to 2 PSU using quadratic regression of the cumulative mortality data.

The growth trial period of 30 days was in accordance with the recommendation of Lazo et al., (2000) that in general, feeding trials involving larvae require 14-28 days, juveniles 6-8 weeks and larger fish 14-18 weeks. Significant differences among the dietary groups were observed at the termination of the feeding trial (Table 5). FI values were in agreement with the results of the attractability test in which QS 45 group exhibited significantly the highest FI value followed by QS 30 group, QS 60 and QS 15 groups (statistically similar, $p>0.05$ ) and $Q S 0$ group exhibiting significantly the lowest FI value $(p<0.05)$ in this decreasing order. FABW, WG, SGR, and FCR of the QS 30 and QS 45 groups were significantly the highest values among all dietary treatments and were not significantly different from each other $(p<0.05)$. In contrast, the significantly lowest values for all the parameters mentioned were exhibited by the QS 0 group $(p<0.05)$ while those of the QS 15 and 60 groups exhibited intermediate values and were not significantly different from each other $(p>0.05)$. The PER values were significantly higher in QS 30 and QS 45 groups than those in the QS 0, QS 15 and QS 60 groups which were not significantly different from each other $(p>0.05)$. Interestingly, survival rate appeared affected by the dietary treatments. Shrimps fed the $Q S$ diets exhibited either statistically similar survival rate with the control group (as in the QS 15 group) or significantly higher survival rate to the control group (all the rest of the $Q S$ groups which were not significantly different from each other, $p>0.05$ ).

Table 5 Growth performance of the black tiger shrimp Penaeus monodon fed with diets containing different concentrations of dietary Quillaja saponin for 30 days.

\begin{tabular}{lccccc}
\hline \multirow{2}{*}{ Index } & \multicolumn{5}{c}{ Treatment } \\
\cline { 2 - 6 } & QS 0 & QS 15 & QS 30 & $Q S 45$ & $Q S 60$ \\
\hline IABW & $0.01 \pm 0.00$ & $0.01 \pm 0.00$ & $0.01 \pm 0.00$ & $0.01 \pm 0.00$ & $0.01 \pm 0.00$ \\
FABW & $0.05 \pm 0.00^{\mathrm{c}}$ & $0.07 \pm 0.00^{\mathrm{b}}$ & $0.08 \pm 0.00^{\mathrm{a}}$ & $0.09 \pm 0.00^{\mathrm{a}}$ & $0.06 \pm 0.00^{\mathrm{b}}$ \\
FI & $0.19 \pm 0.01^{\mathrm{d}}$ & $0.29 \pm 0.01^{\mathrm{c}}$ & $0.42 \pm 0.01^{\mathrm{b}}$ & $0.48 \pm 0.03^{\mathrm{a}}$ & $0.32 \pm 0.02^{\mathrm{c}}$ \\
WG & $0.04 \pm 0.00^{\mathrm{c}}$ & $0.06 \pm 0.00^{\mathrm{b}}$ & $0.07 \pm 0.00^{\mathrm{a}}$ & $0.08 \pm 0.00^{\mathrm{a}}$ & $0.05 \pm 0.00^{\mathrm{b}}$ \\
SGR & $4.71 \pm 0.16^{\mathrm{c}}$ & $6.47 \pm 0.05^{\mathrm{b}}$ & $8.12 \pm 0.19^{\mathrm{a}}$ & $8.57 \pm 0.15^{\mathrm{a}}$ & $6.17 \pm 0.18^{\mathrm{b}}$ \\
PER & $0.28 \pm 0.01^{\mathrm{b}}$ & $0.30 \pm 0.01^{\mathrm{b}}$ & $0.35 \pm 0.00^{\mathrm{a}}$ & $0.34 \pm 0.01^{\mathrm{a}}$ & $0.30 \pm 0.01^{\mathrm{a}}$ \\
FCR & $2.41 \pm 0.11^{\mathrm{c}}$ & $1.63 \pm 0.01^{\mathrm{b}}$ & $1.26 \pm 0.03^{\mathrm{a}}$ & $1.18 \pm 0.02^{\mathrm{a}}$ & $1.73 \pm 0.06^{\mathrm{b}}$ \\
SURV & $64.00 \pm 2.31^{\mathrm{c}}$ & $72.00 \pm 2.3^{\mathrm{bc}}$ & $82.67 \pm 1.33^{\mathrm{ab}}$ & $89.33 \pm 3.53^{\mathrm{a}}$ & $81.33 \pm 3.53^{\mathrm{ab}}$ \\
\hline
\end{tabular}

Values in the same column with different superscript letters are significantly different $(p<0.05)$. Values were expressed as mean \pm SEM, IABW - initial average body weight; FABW - final average body weight; FI - feed intake; WG - weight gain; SGR - specific growth rate; survival - percentage survival; FCR - feed conversion ratio; PER protein efficiency ratio. 
Optimal inclusion rate of Quillaja saponin was estimated by fitting the WG, SGR, and FCR values into a quadratic regression equation separately to have a mean value of 0.36 $\mathrm{g} \mathrm{kg}^{-1} Q S$, (Figure 4).
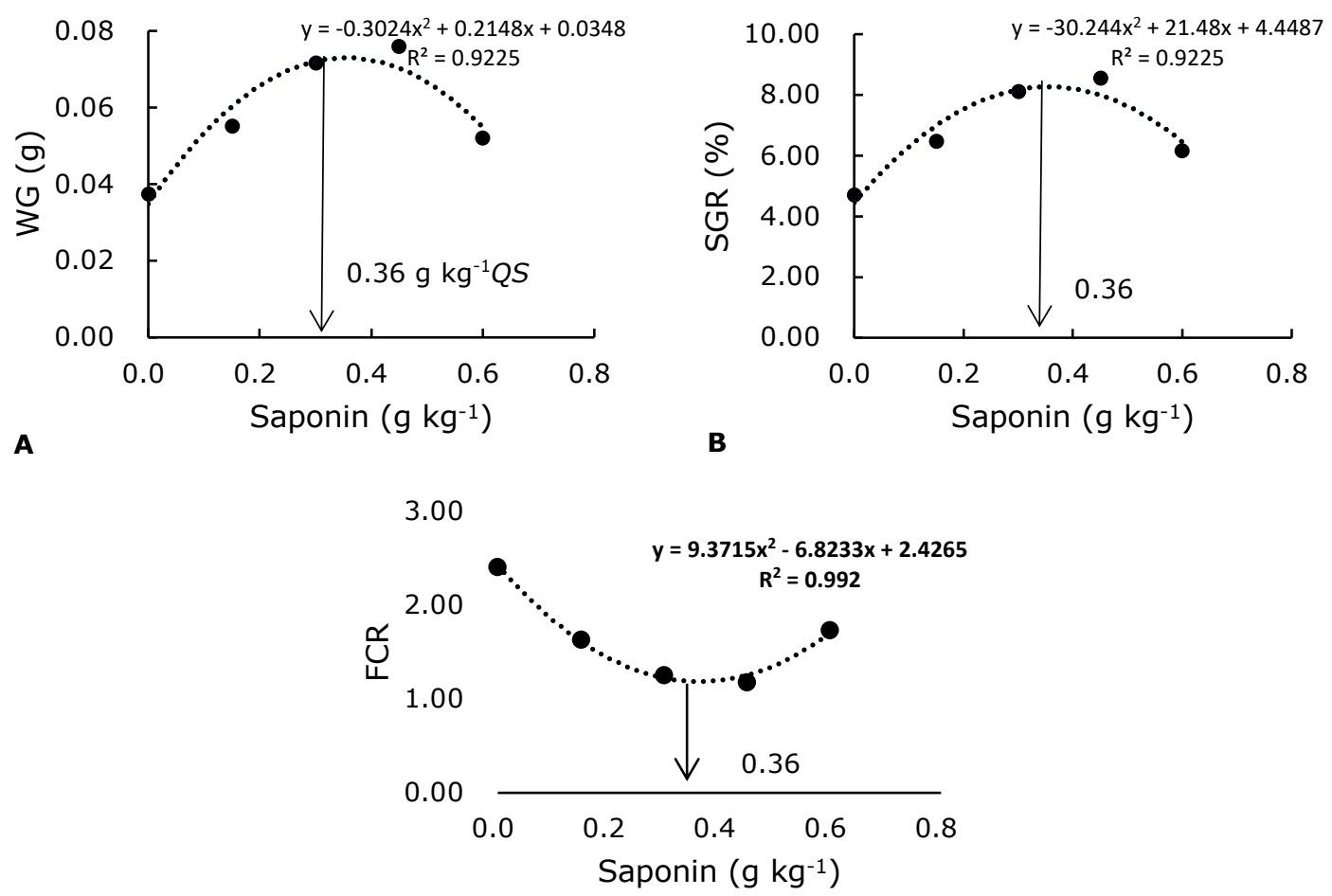

C

Figure 4 Optimal level of Quillaja saponin in the diet determined by fitting weight gain (A), specific growth rate (B) and feed conversion ratio (C) data into a quadratic regression model.

\section{Discussion}

The present study demonstrated that adding $Q S$ to the diet of shrimp increased the attractability of the diet to Penaeus monodon relative to the control diet (i.e. containing no $Q S)$. This is the first report of the direct effect of saponin on diet attractability in either crustacean or fish. $\mathrm{Ng}^{\prime} \mathrm{ambi}$ et al. (2016) demonstrated that saponin enhanced the growth of the swimming crab Portunus trituberculatus but did not isolate its effect on the attractability of the saponin diet. Saponin is the chemical cue that attracts symbionts to their hosts in the marine environment (Caulier et al., 2013). For example, in sea cucumbers, saponin acts as repellent against predators and parasites but they are only colonized by a few marine species, among them is the Harlequin crab Lissocarcinus orbicularis. These investigators revealed for the first time that saponins are the kairomones (i.e. chemical signals emitted by hosts that elicit a commensal or a parasitic symbiosis) secreted by the sea cucumber recognized by the Harlequin crabs in ensuring the symbiosis between them. The success of this symbiosis through evolution, the sea cucumber chemical defences, their repellents (i.e. saponins) becoming powerful attractants.

A few studies on shrimps involved determining the effects of dissolved saponin in the water medium rather than in their diet. Chen et al. (1996) determined the effect of QS on feeding in Penaeus japonicus juveniles by exposing the shrimps in various QS levels 
dissolved in the water medium either for $0.5 \mathrm{~h}$ for adolescent shrimps or $70 \mathrm{~d}$ for shrimp juveniles and measured the feeding rate. Their results showed that the amount of feed $P$. japonicus consumed, regardless of the life stage, declined with increasing saponin concentration. Their experiments departed greatly from the methodology of the present experiment in which QS was incorporated in the diet and was not dissolved in the water medium. Considering that shrimps nibbled on the hard pellet in the present study rather than swallowed the whole particle the way fish do, presumably a negligible amount of $Q S$ leached into the water medium. Effectively, QS in the water medium affects the gill first while that in the diet affects the gut first. Dissolved saponin acts chiefly by lowering the surface tension between water and the gills of fish preventing the uptake of oxygen by the fish and leading to slow death by oxygen deprivation (Lamba, 1970). Furthermore, saponin is considered to cause swelling in the lamella and interlamellar epithelia of gills and affect respiratory epithelium of fish (Roy et al., 1986; Roy \& Munshi, 1989). However, fish have been observed to be more susceptible and sensitive to saponin than shrimps (Terazaki et al., 1990; Minsalan \& Chiu, 1986). Terazaki et al. (1980) reported that the median lethal time (LT50) of saponin at $40 \mathrm{mg} \mathrm{L}^{-1}$ was $0.5 \mathrm{~h}$ for Oreochromis mossambicus and $30 \mathrm{~h}$ for Penaeus merguiensis. The finfish Glossogobius giurus is more sensitive to saponin than Penaeus monodon and Metapenaeus ensis. Chen et al. (1996) found no P. japonicus juvenile died following exposure to saponin at $22.5 \mathrm{mg} \mathrm{L}^{-1}$ for $24 \mathrm{~h}$. In a toxicity test of involving various sea anemone-produced toxins including saponin, Giese et al. (1996) observed that $50 \mu \mathrm{g} \mathrm{mL}^{-1}$ saponin killed fish while as high as $2 \mathrm{mg} \mathrm{mL}^{-1}$ of saponin was ineffective in crustaceans. According to them, this indicates that crustaceans are well protected from cytolytic, e.g. pore forming substances, dissolved in water; this can be explained by the fact that the gill epithelium of crustaceans is covered with a chitin layer forming a barrier, which obviously cannot be penetrated by the toxins, including saponin. Even when saponin were injected into the carapace of the shore crab Metopograpsus oceanicus, at the highest concentration they tested at $100 \mu \mathrm{g} \mathrm{g}^{-1}$, the shore crab survived.

There are a few studies on the growth-enhancing effect of saponin in fish (e.g. Jenkins et al., 1991; Ninomiya et al., 1995; Serrano Jr., 2013; Su and Chen, 2008; Yeh et al., 2006) but are very scarce in crustaceans. There were only two studies on the effect of saponin on crustacean growth. Chen et al. (1996) determined the growth of Penaeus japonicus cultured in various $Q S$ concentrations in the water medium: $0,0.1,0.5,1$ and 2 $\mathrm{mg} \mathrm{L}^{-1}$ and fed with commercial diet for 60 days. FABW was significantly the highest in the control and $0.1 \mathrm{mg} \mathrm{L}^{-1} Q S$ in the water medium and significantly the lowest in 1 and $2 \mathrm{mg}$ $\mathrm{L}^{-1} \mathrm{QS}$ in the water medium; shrimps in $0.5 \mathrm{mg} \mathrm{L}^{-1} Q S$ in the water medium exhibited an intermediate FABW value significantly different from the two groups. The only study with QS directly incorporated in the diet of a crustacean was by $\mathrm{Ng}^{\prime} \mathrm{ambi}$ et al. (2016) who observed that incorporating QS into the diet of the swimming crab Portunus trituberculatus enhanced the growth of the crab. We estimated the optimal inclusion of $Q S$ in the swimming crab from the data of $\mathrm{Ng}^{\prime} \mathrm{ambi}$ et al. (2016) by fitting the FABW data into the quadratic regression equation to be $0.25 \mathrm{~g} \mathrm{~kg}^{-1}$ which was less than what we estimated for the $P$. monodon of $0.36 \mathrm{~g} \mathrm{~kg}^{-1}$ in the present study. In common carp, the ratios of the activities of the aerobic enzyme cytochrome c-oxidase (Cox) to those of the anaerobic enzyme lactate dehydrogenase (LDH) were increased from 2.3 in QS 0 to 3.0, 3.7 and 3.3 in $Q S 15, Q S 30$ and QS 45 indicating that there was a net energy accumulation due to a higher rate of anabolic over that of the catabolic processes (Serrano, 2013). This observation is similar in Penaeus monodon in the present study which could explain the net growth of shrimps in groups supplemented with QS.

The optimal dietary level for maximal growth $\left(0.36 \mathrm{~g} \mathrm{~kg}^{-1} \mathrm{QS}\right)$ was very close to the level that could elicit maximal resistance to low salinity shock estimated to be $0.33 \mathrm{~g} \mathrm{~kg}^{-1}$ QS. Thus, at $0.36 \mathrm{~g} \mathrm{~kg}^{-1}$ QS would function both as growth promoter as well as immune enhancer against low salinity shock. As far as we know, there has been no direct study on the effect of dietary saponin on the resistance of a crustacean against acute hyposalinity 
stress but there are a few on the effects of acute salinity stress on the immunocompetence (Joseph \& Philip, 2020) and transcriptomic response (Shekkar et al., 2013) in P. monodon. Transferring $P$. monodon from $15 \mathrm{ppt}$ medium to $5 \mathrm{ppt}$ medium after $7 \mathrm{~h}$ resulted in reduced total haemocyte count (THC), phenoloxidase (PO) activity, nitroblue tetrazolium salt, alkaline phosphatase (ALP) activity and acid phosphatase (ACP) activity (Joseph \& Philip, 2020). On the other hand, feeding a diet containing $Q S$ in the swimming crab Portunus trituberculatus then challenging them with $V$. algynolyticus resulted in an increased THC, PO at $0.45 \mathrm{~g} \mathrm{~kg}^{-1}$ QS, SOD, CAT, GPx and phagocytic activities (Ngambi et al., 2016). In L. vannamei, immersion in saponin resulted in increased THC, alpha-2-macroglobulin, respiratory burst (RB, equivalent to NBT), superoxide dismutase) SOD, glutathione peroxidase (GPX) and phagocytic activities; however, PO activity was decreased by the saponin immersion (Su \& Chen, 2008). Indirectly, it appears that the decreased immune response indices measured in $P$. monodon when subjected to hyposalinity stress by Joseph \& Philip (2020) could be counteracted by feeding a diet containing saponin as was demonstrated in L. vannamei (Su \& Chen, 2008) and in Portunus trituberculatus ( $\mathrm{Ng}^{\prime}$ ambi et al., 2016). This could also be the mechanism behind our observation of significantly low cumulative mortality in $P$. monodon fed QS 30 and 45 in the present study.

In conclusion, dietary Quillaja saponin enhanced the attractability of experimental diets relative to the control diet with the dose of $0.45 \mathrm{~g} \mathrm{~kg}^{-1} \mathrm{QS}$ attracting the most number of shrimps. Dietary Quillaja saponin resulted in better growth and efficiency than did the control diet, and at inclusion levels of 0.30 and $0.45 \mathrm{~g} \mathrm{~kg}^{-1}$ elicited maximal growth and efficiency; no additional benefits at lower and higher dietary levels (i.e. 0.15 and $0.60 \mathrm{~g}$ $\mathrm{kg}^{-1} Q S$ ). QS also affected survival rate starting from 0.30 to $0.6 \mathrm{~g} \mathrm{~kg}^{-1}$; at the low dosage of $0.15 \mathrm{~g} \mathrm{~kg}^{-1} Q S$, there was no significant increase in the survival rate over that of the control group. The optimal inclusion level of dietary Quillaja saponin for maximum growth and efficiency was estimated to be $0.36 \mathrm{~g} \mathrm{~kg}^{-1}$ employing the second level polynomial regression of WG, SGR and FCR data. This dosage was very close to the level that elicited maximal protection against acute hyposalinity stress which was $0.33 \mathrm{~g} \mathrm{~kg}^{-1}$.

\section{Acknowledgments}

The principal author acknowledges the funding supports of the following institutions: Graduate Research and Education Assistantship for Technology (GREAT) Program of the DOST-PCAARRD, UPV - Office of the Vice-Chancellor for Research and Extension (UPVOVCRE) for the partial dissertation grant and the Mindanao State University Tawi-Tawi College of Technology and Oceanography - Academic Personnel Development Program (MSU-TCTO, APDP). Gratitude is due to Arlie Nim, Vicente Nim, Apple Gray Deallo and Pearl Joy Laureano for technical and administrative assistance.

\section{References}

Acosta, R., Rosen, Y., Ariav, R., 2019. The use of saponins in aquaculture. International Aquafeed. August 2019. Perendale Publishers, Ltd., pp. 32-37.

Awad, E., Awaad, A., 2017. Role of medicinal plants on growth performance and immune status in fish. Fish \& Shellfish Immunology 67: 40-54. https://doi.org/10.1016/j.fsi.2017.05.034.

Caulier, G., Flammang, P., Gerbaux, P., Eeckhaut, I., 2013. When a repellant becomes an attractant: harmful saponins are kairomones attracting the symbiotic Harlequin crab. Scientific Reports, 3: 2639. DOI: 10.1038/srep02639

Chang, Y.P., Liu, C.H., Wu, C.C., Chiang, C.M., Lian, J.L., Hsieh, S.L., 2012. Dietary administration of zingerone to enhance growth, non-specific immune response, and resistance to Vibrio alginolyticus in Pacific white shrimp (Litopenaeus vannamei) juveniles. Fish \& Shellfish Immunology 32(2): 284-290. https://doi.org/10.1016/j.fsi.2011.11.017. 
Chen, J.C., Lin, J.L., 1994. Osmolality and chloride concentration in the hemolymph of subadult Penaeus chinensis subjected to different salinity level. Aquaculture 125: 167-174. https://doi.org/10.1016/0044-8486(94)90293-3.

Chen, J.C., Lin, M.N., Ting, Y.Y., Lin, J.N., 1995. Survival, haemolymph osmolality and tissue water of Penaeus chinensis juvenile acclimated to different salinity and temperature levels. Comparative Biochemistry and Physiology A 110: 253-258. https://doi.org/10.1016/0300-9629(94)00164-O.

Chen, J.C., Chen, K.W., Chen, J.M., 1996. Effects of saponin on survival, growth, molting and feeding of Penaeus japonicus juveniles. Aquaculture 144, 165-175. https://doi.org/10.1016/S0044-8486(96)01301-4.

Chen, J.-C., Lin, J.-N., Chen, C.-T., Lin, M.-N., 1996. Survival, growth and intermolt period of juvenile Penaeus chinensis (Osbeck) reared at different combinations of salinity and temperature. Journal of Experimental Marine Biology and Ecology 204(1-2): 169-178. https://doi.org/10.1016/0022-0981(96)02589-0.

Chen, Q., Zhang, Y., Zhao, Q., 2020. Expression analysis of immune-associated genes in hemocytes of mud crab Scylla paramamosain under low salinity challenge. Fish \& Shellfish Immunology (in press) https://doi.org/10.1016/j.fsi.2020.09.021.

Ferraris, R.P., Parado-Estepa, F.D., De Jesus, E.G., Ladja, J.M., 1986. Osmotic and chloride regulation in the haemolymph of the tiger prawn Penaeus monodon during molting in various salinities. Marine Biology 95:377-85.

Giese, C., Mebs, D., Werding, B., 1996. Resistance and vulnerability of crustaceans to cytolytic sea anemone toxins. Toxicon 34: 955-958. https://doi.org/10.1016/00410101(96)00051-7.

Homechaudhuri, S., Banerjee, S., 1991. Scanning electron microscopic observations on the blood cells of common carp (Cyprinus carpio) and the catfish (Heteropneustes fossilis) under piscicide toxicity. Asian Fisheries Science 4(2): 263-267.

Jenkins, P.G., Harris, J.E., Pulsford, A.L., 1991. Enhanced enteric uptake of human gamma globulin by Quil-A saponin in Oreochromis mossambicus. Fish \& Shellfish Immunology 1(4): 279-295. https://doi.org/10.1016/S1050-4648(05)80066-X.

Joseph, A., Philip, R., 2020. Immunocompetence of Penaeus monodon under acute salinity stress and pathogenicity of Vibrio harveyi with respect to ambient salinity. Fish \& Shellfish Immunology 106: 555-562. https://doi.org/10.1016/j.fsi.2020.07.067.

Lamba, S.S., 1970. Indian piscicidal plants. Economic Botany 24: 134-136.

Lazo, J.P., Davis, D.A., 2000. Ingredient and feed evaluation. In: Stickney, R.R. (ed.) Encyclopedia of Aquaculture. John Wiley \& Sons, Inc., NY, USA. pp. 453-464.

Liu, X.L., Xi, Q.Y., Yang, L., Li, H.Y., Jiang, Q.Y., Shu, G., Wang, S.B., Gao, P., Zhu, X.T., Zhang, Y.L., 2011. The effect of dietary Panax ginseng polysaccharide extract on the immune responses in white shrimp, Litopenaeus vannamei. Fish \& Shellfish Immunology 30(2): 495-500. https://doi.org/10.1016/j.fsi.2010.11.018.

Logambal, S.M., Venkatalakshmi, S., Michael, R.D., 2000. Immunostimulatory effect of leaf extract of Ocimum sanctum Linn. in Oreochromis mossambicus (Peters). Hydrobiologia 430, 113-120. https://doi.org/10.1023/A:1004029332114.

Kongchum, P., Chimtonga, S., Chareansaka, N., Subpraserta., P., 2016. Effect of green tea extract on Vibrio parahaemolyticus inhibition in Pacific White Shrimp (Litopenaeus vannamei) postlarvae. Agriculture and Agricultural Science Procedia 11: 117124. doi: 10.1016/j.aaspro.2016.12.020.

Minsalan, C.O., Chiu, Y.N., 1986. Effects of tea seed cake on selective elimination of finfish in shrimp ponds. In: Maclean, J.L., Dizon, I.B., Hosillos, L.V. (Eds.), The First Asian Fisheries Forum. Asian Fisheries Society, Manila, Philippines, pp. 79-82.

Nikapitiya, C., Kim, W.-S., Park, K., Kwak, I.-S., 2014. Identification of potential markers and sensitive tissues for low or high salinity stress in an intertidal mud crab (Macrophthalmus japonicus). Fish \& Shellfish Immunology 41:407-416. doi: 10.1016/j.fsi.2014.09.018.

Ninomiya, M., Hattaa, H., Fujiki, M., Kim, M., Yamamoto, T., Kusuda, R., 1995. Enhancement of chemotactic activity of yellowtail (Seriola quinqueradiata) leucocytes by 
oral administration of quillaja saponin. Fish \& Shellfish Immunology 5(4): 325-328. https://doi.org/10.1006/fsim.1995.0031.

Ng'ambi, J.W., Li, R., Mu, C., Song, W., Liu, L., Wang, C., 2016. Dietary administration of saponin stimulates growth of the swimming crab Portunus trituberculatus and enhances its resistance against Vibrio alginolyticus infection. Fish \& Shellfish Immunology, 59: 305311. https://doi.org/10.1016/j.fsi.2016.10.041

Perazzolo, L.M., Gargioni, R., Ogliari, P., Barracco, M.A.A., 2002. Evaluation of some hematoimmunological parameters in the shrimp Farfantepenaeus paulensis submitted to environmental and physiological stress. Aquaculture 214:19-33. DOI: 10.1016/S00448486(02)00137-0.

Oda, K., Matsuda, H., Murakami, T., Katayama, S., Ohgitani, T., Yoshikawa, M. 2003. Relationship between adjuvant activity and amphipathic structure of soyasaponins. Vaccine 21(17-18): 2145-2151. doi: 10.1016/S0264-410X(02)00739-9.

Roy, P.K., Munshi, J.P., 1989. Effect of saponin extracts on oxygen uptake and hematology of an-breathing climbing perch, Anabas testudineus (Bloch). Journal of Freshwater Biology 1: 167-172.

Roy, P.K., Munshi, J.S.D., Munshi, D.J., 1986. Scanning electron microscope evaluation of effects of saponin on gills of the climbing perch, Anabas testudineus (BlochI (Anabantidae: Pisces). Indian Journal of Experimental Biology 24: 51 l-516.

Roy, P.K., Munshi, J.D., Dutta, H.M., 1990. Effect of saponin extracts on morphohistology and respiratory physiology of an air-breathing fish, Heterapneustes fossilis (Bloch). Journal of Freshwater Biology 2: 135-145.

Serrano Jr., A.E., 2013. Effects of Quillaja saponins on growth, feed efficiency, digestive enzyme activities and metabolism of common carp (Cyprinus carpio L). Aquaculture Nutrition, 19: 468-474. https://doi.org/10.1111/j.1365-2095.2012.00980.x

Silva, E., Calazans, N., Soares, M., Soares, R., Peixoto, S., 2010. Effect of salinity on survival, growth, food consumption and haemolymph osmolality of the pink shrimp Farfantepenaeus subtilis (Pérez-Farfante, 1967). Aquaculture 306: 352-356. doi:10.1016/j.aquaculture.2010.04.025.

Staples, D.J., Heales, D.S., 1991. Temperature and salinity optima for growth and survival of juvenile banana prawns Penaeus merguiensis. Journal of Experimental Marine Biology and Ecology 154:251-74. https://doi.org/10.1016/0022-0981(91)90168-V.

Su, B.K., Chen, J.C., 2008. Effect of saponin immersion on enhancement of the immune response of white shrimp Litopenaeus vannamei and its resistance against Vibrio alginolyticus. Fish \& Shellfish Immunolgy 24: 74-81. doi:10.1016/j.fsi.2007.09.002.

Suresh, A.V., Kumaraguru vasagam, K.P.K, Nates, S., 2011. Attractability and palatability of protein ingredients of aquatic and terrestrial animal origin, and their practical value for blue shrimp, Litopennaeus stylirostris, fed diets formulated with high levels of poultry byproduct meal. Aquaculture, 319: 132-140.

https://doi.org/10.1016/j.aquaculture.2011.06.039

Terazaki, M., Tharnbuppa, P., Nakayama, Y., 1980. Eradication of predatory fishes in shrimp farms in utilization of Thai tea seed. Aquaculture 19, 235-242. https://doi.org/10.1016/0044-8486(80)90047-2.

Wang, W.N., Wu, J., Su, S.J., 2008. Effects of salinity stress on antioxidant enzymes of Penaeus monodon of two different life stages. Comparative Biochemistry and Physiology $\begin{array}{llllll}\text { Part } \quad \text { C:Toxicology } \quad \& \quad \text { Pharmacology } & 148(4): & 466 .\end{array}$ https://doi.org/10.1016/j.cbpc.2008.10.069.

Ye, L., Jiang, S., Zhu, X., Yang, Q., Wen, W., Wu, K., 2009. Effects of salinity on growth and energy budget of juvenile Penaeus monodon. Aquaculture 290: 140-144. doi:10.1016/j.aquaculture.2009.01.028.

Yeh, S.P., Liu, C.H., Sung, T.G., Lee, P.P., Cheng, W., 2006. Effect of saponin on hematological and immunological parameters of the giant freshwater prawn, Macrobrachium rosenbergii. Aquaculture 261: 1432-1439. doi:10.1016/j.aquaculture.2006.08.051. 
Yin, X.L., Li, X.J., Yang, K., Yang, K., Lin, H.Z., Guo, Z.X., 2014. Effect of guava leaves on growth and the non-specific immune response of Penaeus monodon. Fish \& Shellfish Immunology 40: 190-196. https://doi.org/10.1016/j.fsi.2014.07.001.

Wang, F.-I., Chen, J.-C., 2006. Effect of salinity on the immune response of tiger shrimp Penaeus monodon and its susceptibility to Photobacterium damselae subsp. damselae. Fish \& Shellfish Immunology 20:671-681. DOI 10.1186/s40064-016-1878-1.

Wang, W.-N., Wu, J., Su, S-J., 2008. Effects of salinity stress on antioxidant enzymes of Penaeus monodon of two different life stages. Comparative Biochemistry and Physiology $\begin{array}{lllll}\text { Part C: } \quad \text { Toxicology } \quad \text { C } & \text { Pharmacology } & \text { 148(4): }\end{array}$ https://doi.org/10.1016/j.cbpc.2008.10.069. 